Fixed Point Theory, 22(2021), No. 1, 327-342

DOI: $10.24193 /$ fpt-ro.2021.1.23

http://www.math.ubbcluj.ro/ nodeacj/sfptcj.html

\title{
FIXED POINT OF MULTIVALUED CONTRACTIONS BY ALTERING DISTANCES WITH APPLICATION TO NONCONVEX HAMMERSTEIN TYPE INTEGRAL INCLUSIONS
}

\author{
HEMANT KUMAR PATHAK* AND ISMAT BEG** \\ * School of Studies in Mathematics, \\ Pt. Ravishankar Shukla University Raipur (C.G.), 492010, India \\ E-mail: hkpathak05@gmail.com \\ ** Centre for Mathematics and Statistical Sciences, \\ Lahore School of Economics, Lahore 53200, Pakistan \\ E-mail: ibeg@lahoreschool.edu.pk
}

\begin{abstract}
A new contraction condition for multivalued maps in metric spaces is introduced and then, based on this new condition, we prove two fixed point theorems for such contractions. The new condition uses the altering distance technique and a Pompeiu type metric on the family of nonempty and closed subsets of a metric space. Our results essentially compliments and generalizes some well known results. As application, we model a nonconvex Hammerstein type integral inclusion and prove an existence theorem for this problem.
\end{abstract}

Key Words and Phrases: Fixed point, metric space, Hausdorff metric, multivalued contraction, Hammerstein type integral inclusion.

2020 Mathematics Subject Classification: 47H04, 47H10, 47H30, 45G10, 47H20, 45J05, 45P05, $54 \mathrm{H} 25,47 \mathrm{G} 20$.

Acknowledgements. Authors are deeply thankful to the referee for his/her helpful and perceptive suggestions to improve the paper. The research of Hemant Kumar Pathak was supported by University Grants Commission, New Delhi, F. No. 43422/2014 (SR) (MRP-MAJOR-MATH-2013-18394).

\section{REFERENCES}

[1] I. Beg, A. Azam, Fixed points of asymptotically regular multivalued mappings, J. Austral. Math. Soc. (Series-A), 53(1992), no. 3, 313-326.

[2] I. Beg, A.R. Butt, Fixed point for set valued mappings satisfying an implicit relation in partially ordered metric spaces, Nonlinear Anal., 71(2009), 3699-3704.

[3] I. Beg, H.K. Pathak, A variant of Nadler's theorem on weak partial metric spaces with application to a homotopy result, Vietnam J. Math., 46(2018), no. 3, 693-706.

[4] C. Castaing, M. Valadier, Convex Analysis and Measurable Multifunctions, LNM 580, Springer, Berlin, 1977.

[5] Y. Feng, S. Liu, Fixed point theorems for multivalued contractive mappings and multivalued Caristi type mappings, J. Math. Anal. Appl., 317(2006), 103-112. 
[6] T. Kamran, Q. Kiran, Fixed point theorems for multivalued mappings obtained by altering distances, Mathematical and Computer Modelling, 54(2011), 2772-2777.

[7] W.A. Kirk, N. Shahzad, Fixed Point Theory in Distance Spaces, Springer, Switzerland, 2014.

[8] D. Klim, D. Wardowski, Fixed point theorems for set-valued contractions in complete metric spaces, J. Math. Anal. Appl., 334(2007), 132-139.

[9] Z. Liu, X. Na, Y.C. Kwun, S.M. Kang, Fixed points of some set-valued F-contractions, J. Nonlinear Sci. Appl., 9(2016), 5790-5805.

[10] N. Mizoguchi, W. Takahashi, Fixed point theorems for multivalued mappings on complete metric spaces, J. Math. Anal. Appl., 141(1989), 177-188.

[11] S.B. Nadler Jr., Multivalued contraction mappings, Pacific J. Math., 20(1969), 475-488.

[12] H.K. Pathak, N. Shahzad, Fixed point results for set valued contractions by altering distances in complete metric spaces, Nonlinear Anal., 70(2008), 2634-2641.

[13] H.K. Pathak, N. Shahzad, A new fixed point result and its application to existence theorem for nonconvex Hammerstein type integral inclusion, Electronic J. Qualitative Theory of Differential Equations, 62(2012), 1-13.

[14] A. Petruşel, Operatorial Inclusions, House of the Book of Science, Cluj-Napoca, 2002.

[15] S. Reich, Fixed points of contractive functions, Boll. Unione Mat. Ital., 5(1972), 26-42.

[16] S. Reich, Some fixed point problems, Atti Acad. Naz. Lincei, 57(1974), 194-198.

[17] X. Zhang, Common fixed point theorems for some new generalized contractive type mappings, J. Math. Anal. Appl., 333(2007), 780-786.

Received: January 29, 2019; Accepted: January 28, 2020. 